\title{
What is a "Sebastian"? A nonsensical look at the poetry of Yona Wallach
}

\author{
Ailor Porat \\ Department of Hebrew Literature, Ben-Gurion University of the Negev \\ Ailor10@gmail.com
}

\begin{abstract}
This article compares the nonsensical narrative of Lewis Carroll to the poetry of the canonical Hebrew poet, Yona Wallach. Both writers seek to establish a unique and differentiated poetic logic, a logic that "makes sense" in its own way. Unlike Carroll, in the mid 1960s Yona Wallach presented an adult audience with Hebrew poetry which is mostly regarded as "serious", even tragic, with a "doom-like" quality hovering over it. Nonetheless, a comparison between Yona Wallach and Lewis Carroll discloses their surprising likeness. They both employ similar mechanisms of nonsensical linguistic games. As I will demonstrate, both Wallach and Carroll play with the conventional meaning of words and use them in an incongruous, anti-commonsensical, manner. Throughout the article, Carroll's work will reveal its serious and gloomy quality, whereas Wallach's work will reveal its (rarely discussed) logical and amusing quality. Thus, the contrast between Carroll's work and Wallach's poetry sheds light on their respective mechanisms of signification and humourmaking, in a manner indiscernible when each is treated independently.
\end{abstract}

Keywords: Lewis Carroll, Yona Wallach, nonsense, modernist poetry, language-games.

\section{Introduction}

In his article "What is a Boojum? Nonsense and Modernism", Michael Holquist describes Lewis Carroll's affinity for the "serious" modern art written in the $20^{\text {th }}$ century. He comments on how, while reading the works of authors very different from Carroll, such as Kafka or Joyce, Carroll's concluding line from The Hunting of the Snark - "For the Snark was a Boojum, you see" - recurrently passed through his mind. Accounting for this association, he claims that Carroll's works illustrate one of modern literature's most distinctive features: its resistance to allegorical reading. To him, the Snark best dramatizes the desire to create an immaculate fiction, a fiction that resists any attempts of the readers to recognise in it the already-existing language in the non-fictive world. Nonsense, in the writings of Lewis Carroll, is a closed field of language. It is its own system of signs. The poem - and ensuing modern art - is, in a small way, its own language (Holquist 1999 [1969]). 
The early poetics of the canonical Hebrew poet Yona Wallach (1944-1985) appears to correspond to this literary continuum. ${ }^{1}$ Wallach began publishing her work in the $1960 \mathrm{~s}$. In her books Things (1966) and Two Gardens (1968), she created poems which are not based on the logic of conventional reality, but rather on systems of unfamiliar, psychedelic, and "dreamlike" logic. ${ }^{2}$ As claimed by Tsafrira Lidovski-Cohen, her poems present "a concrete, 'realistic' situation", combined with "exotic imagery", and generate an "instant glimpse into an existential plight of an innocent human being trapped in an unintelligible world" (Lidovsky-Cohen 2003: 45).

Nonsense literature similarly "earned" such descriptions, notably Lewis Carroll's classic and paradigmatic Alice's Adventures in Wonderland (1865) and Through the Looking Glass and What Alice Found There (1871). ${ }^{3}$ Both novels - also described as psychedelic in the spirit of the $60 \mathrm{~s}^{4}$ - recount the tale of a little girl who enters a surreal, peculiar, dreamlike world, subscribing to its own logic.

However, as Elizabeth Sewell explains, nonsense literature and nonsense logic are far from being a "haphazard meaningless dream". Nonsense is not chaotic, instead it is "a collection of words of events which in their arrangement do not fit into some recognized system" (Sewell 1952: 25), but which constitute a new system of their own. ${ }^{5}$ These new systems operate as a logical game. The meticulously formal abstract structure dominates over the "mad" content and even dictates it, much like in mathematics. ${ }^{6}$

Sewell has claimed that Carroll's illustrious Victorian literature - especially poems like "Jabberwocky" - is too logical and precise to be considered "real" poetry. His literature is essentially of a comic and playful nature (Sewell 1952: 25). The humour operating through his texts derives from the incongruous struggle against common sense, which establishes an alternative logic. ${ }^{7}$ It is also of an ambivalent nature. Zohar Shavit, a scholar engaged with children's literature, explains that the Alice books are "ambivalent" on the grounds of their simultaneous reception by two different target audiences, children and adults, with the latter reading into them and suggesting multiple "serious" and diverse meanings (Shavit \& EvenZohar 1996).

Unlike Carroll, Yona Wallach, in the mid-60s, wrote Hebrew poetry for adults, which is mostly regarded as "serious", even tragic, with a "doom-like" quality hovering over it (Lidovski-Cohen 2003). Lily Rattok describes this poetry as inclined towards ambiguity and the "undefinable"; it is poetry marked by an abrupt transition between different linguistic registers, by the apparent absence of punctuation and by a fractured incorrect syntax, which entail multiple readings (Rattok 1997). ${ }^{8}$

Nonetheless, and precisely because of their considerable dissimilarity, the comparison between Yona Wallach and Lewis Carroll discloses their surprising likeness. As I will demonstrate, both Wallach and Carroll play with the conventional meaning of words and use them in an incongruous, anti-commonsensical, manner. My present article will point out two similar mechanisms of nonsensical linguistic games. Aware of the hazards of comparison, I suggest a reading focused on a limited corpus of Wallach's and Carroll's texts exhibiting similar elements.

The first comparison juxtaposes the meta-poetic figure of Humpty Dumpty in Through the Looking Glass with Wallach's meta-poetic cycle "Precisely" (Bediyuk Nimratz), exposing both writers' redefining meaning of words in an arbitrary and playful manner. The second juxtaposes the illogical and tragic childish beheading in Wallach's "Yonatan" with the illogical and playful childish beheading embodied in the figure of the Queen of Hearts in Wonderland.

Throughout this article, Carroll's work shall reveal its serious and gloomy quality, where Wallach's work will reveal its (rarely discussed) logical and amusing quality. Thus, the contrast between Carroll's work and Wallach's poetry will shed light on their respective 
mechanisms of signification and humour-making, in a manner indiscernible when each is treated independently.

\section{Which is to be master?}

Yona Wallach is an Israeli "cultural legend", as Tsafrira Lidovsky-Cohen claims in the opening of her book Loosen the Fetters of Thy Tongue, Woman (2003). Wallach is regarded by many to be the most prominent among young Israeli poets of the $1960 \mathrm{~s}$, and perhaps the greatest Hebrew poet of modern times, as well as a groundbreaker for female poets in a maledominated poetic landscape. She has had a tremendous effect on Israel's cultural life since the publication of her work. Words like "sexy", "mad", and "mystical" are only some of the few applied in describing her work. Wallach is equally remembered for her extravagant, semi-crazy, provocative personality and for her sensational life, which stood out in conservative Israel of that time. Her life seems to have epitomized the "flower children" counterculture, involving drugs, sexual experimentation and gender fluidity, and stints in mental institutions.

As Anat Weisman describes, Yona Wallach is perhaps the single example in Israeli poetry where the attitude towards her persona and her poetry is described in cultic terms (Weissman 2014: 377-380). Wallach's personality cult depicts her as a one-time, ahistorical cultural hero who cropped up "rootless". She is often portrayed as a one-of-a-kind speaker, a "master of all words", as if she were First Man - and her function is not to be imitative of an already existent reality, but rather to build and establish a new reality. ${ }^{9}$

Her first book abounds with "character poems". The titles of the poems bear exotic, enigmatic and intriguing names to the Hebrew language, such as Cecilia, Cornelia, and Nizeta; and their narratives typically portray the characters as they wander through a hazy psychedelic landscape. Extensive interpretative debate surrounds the meaning of these foreign names in Wallach's poetry, which create a seemingly anti-referential, idiosyncratic, and enigmatic private language. Yael Renan defines Wallach's early poetry as an "embodiment of a concrete emotional standpoint" via the personal "name-giving" which assigns subjective meanings to inner sensations (Renan 1976). By contrast, the first-name system is in part remindful of names of Christian saints, as has been indicated by some scholars who attempted to read Wallach in a more historical and less "private" context (e.g. Tsamir 2006; Rattok 1997).

This principle is prominent in the poem "Sebastian", notable for its particularly interesting use of stipulative rules in the personal name game that breaks the categories of signification:

Sebastian

Of Sebastian
that never was
neither in form
Sebastian is
a malady tender in warmth
And compassion
I wanted to raise to its name
something that would realize Sebastian
something like
a house for archers
with slits through which one sees a pink city
but to think right from the start




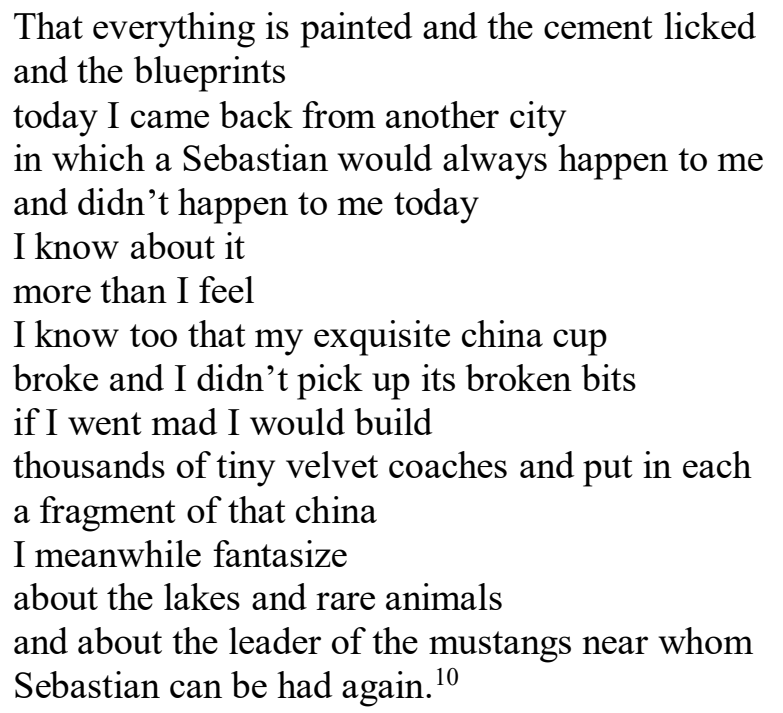

Throughout the poem it becomes clear that the meaning of the word "Sebastian" differs here from the conventional lexical sense of the proper name "Sebastian". The speaker relates to him as "it" rather than "he". This is problematic specifically in Hebrew, a language which, unlike English, has no neutral, gender-free, pronouns (a fact that propelled Wallach to write, in one of her most famous poems, that Hebrew is a "Sex-maniac" language). The English translation shows some equivalency by referring to "Sebastian" - a proper name, meant to denote a unique person - as "a Sebastian", a common noun.

The speaker reveals that "a Sebastian" is on the one hand what "would always happen" to her, and on the other, that it "never was" and is again possible only when near the "leader of the mustangs". She thereby creates an ontological problem, of something which concurrently exists and is non-existent.

The interpretive problem presented by the naming mechanism in the poem is reminiscent of Carroll's Humpty Dumpty. The character made one of its first appearances in a Mother Goose nursery rhyme, as an egg-shaped figure perched on a wall. In Carroll's Through the Looking Glass, Humpty is symbolic of hubris: he is arrogant, egocentric, perched on the wall boasting, and perceives himself as "the master of words". His figure affords a glimpse into a nonsense mechanism whereby any speaker can assign any word with any meaning he/she likes:

'There's glory for you!'

'I don't know what you mean by "glory", Alice said.

Humpty Dumpty smiled contemptuously. 'Of course you don't—till I tell you. I meant "there's a nice knock-down argument for you!",

'But "glory" doesn't mean "a nice knock-down argument", Alice objected.

'When I use a word', Humpty Dumpty said in rather a scornful tone, 'it means just what I choose it to mean - neither more nor less.'

'The question is', said Alice, 'whether you can make words mean so many different things.'

'The question is', said Humpty Dumpty, 'which is to be master - that's all.'

Alice was too much puzzled to say anything, so after a minute Humpty Dumpty began again. 'They've a temper, some of them-particularly verbs, they're the proudest - adjectives you can do anything with, but not verbs - however, I can manage the whole lot of them! Impenetrability! That's what $I$ say!'

(Carroll 1962 [1871]: 274-275)

Humpty's arrogance leads him to perceive himself as "Adam" - the First Man - to entertain the illusion that language provides him with control and linguistic omnipotence, as suggested 
by Jean-Jacques Lecercle (1994). This self-perception is sustained until the moment of his deterministic, fatal, and inevitable fall off the wall - a moment exposing the tragic struggle in which he is caught, between the mastery of private language and the enslavement to the bad "temper" of words dictating his world. Instructive of this is the Looking Glass dialogue, when Humpty Dumpty asks, "which is to be master" - whether the speakers or the words they employ - "that's all". This question, as Lecercle explains, is one of the fundamental queries in the philosophical readings of these books. ${ }^{11}$

Expressive of Humpty's struggle for linguistic omnipotence is his attempt to redefine words, to invest them with a stipulative meaning, any meaning he wants, instead of their lexical, commonplace (and social) meaning. ${ }^{12}$ This notion also emerges from how Lewis Carroll himself conceived language, a concept he expressed on other platforms:

...I maintain that any writer of a book is fully authorized in attaching any meaning he likes to any word he intends to use. If I find an author saying at the beginning of his book, "Let it be understood that by the word white I shall always mean black" I meekly accept his ruling, however injudicious I may think it.

(Carroll 1977 [1896]: 59)

Humpty's figure, as Michael Hancher explains, veers between two extremes (Hancher 1981: 49-58). On the one hand, some scholars accuse him of a radical conception of language, ${ }^{13}$ much like the notoriously impossible private language of Ludwig Wittgenstein. ${ }^{14}$ On the other, Humpty explains to Alice the mechanism of his word use, which makes him remarkably communicative (Hancher 1981: 49-58). Indeed, Humpty (as a projection of Carroll himself) is concerned that Alice will "accept his ruling" - namely, use words in the sense he determined. According to this logic, he interprets for Alice the nonsensical words of the poem "Jabberwocky" (telling her "Of course you don't— till I tell you"). ${ }^{15}$

Humpty's unique linguistic "mastery" is also implied in his description as sui generis, a figure belonging to no category but his own. The original Mother Goose poem is a riddle, asking "What is Humpty Dumpty?", as he is not actually an egg. In Through the Looking Glass, he is assigned human features (hands, eyes, nose, and mouth) and becomes angry when Alice calls him an egg, as he belongs to no existing category and creates a new one in himself. On approaching him, Alice easily recognizes him by his facial features: "she saw clearly that it was Humpty Dumpty himself. 'It can't be anybody else!' she said to herself. 'I'm certain of it, as if his name were written all over his face"" (Carroll 1962 [1871]: 267). And as they converse, he confirms he is indeed Humpty Dumpty and points out his uniqueness: "Now, take a good look at me! I'm one that has spoken to a King, I am: mayhap you'll never see such another" (Carroll 1962 [1871]: 270).

Humpty's uniqueness is set off against the non-distinctive figure of Alice, who, to his mind, is hardly recognizable or identifiable:

'I shouldn't know you again if we did meet', Humpty Dumpty replied in a discontented tone, giving her one of his fingers to shake; 'you're so exactly like other people'.

(Carroll 1962 [1871]: 282)

She would be distinguishable, according to Humpty, by her facial features:

'The face is what one goes by, generally', Alice remarked in a thoughtful tone. 'That's just what I complain of', said Humpty Dumpty. 'Your face is the same as everybody has - the two eyes, so-' (marking their places in the air with this thumb) 'nose in the middle, mouth under. It's always the same. Now if you had the two eyes on the same side of the nose, for instance- or the mouth at the top - that would be some help'.

(Carroll 1962 [1871]: 282) 
Against the meta-poetic character of Humpty Dumpty, which attempts to depict the speaker and author as the amused "master of words" with the one-of-a-kind face, we have Yona Wallach's poetry and her idiosyncratic mechanism of naming. She, much like Humpty, is known by her mythical persona, where she is portrayed as a one-of-a-kind, "master of all words". And much like him - as I will proceed to show - Wallach herself explains the meaning of these odd names - which turns out to be an arbitrary, stipulative, and surprisingly amusing hoax - in a manner reminiscent of Humpty's interpretative mechanism of the Jabberwocky. She provides this explanation in the following meta-poetic confession:

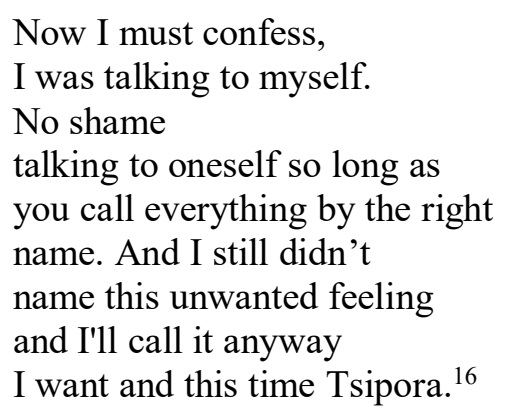

This poem is third in the cycle called "Precisely". As Zafrira Lidovsky-Cohen suggests, the first two parts of this poetic cycle appear to be concerned with matters "between him and her", ${ }^{17}$ whereas the third part reveals the poem is meta-poetic and aims at presenting the poet's critical perspective on language (Lidovsky-Cohen 2003).

The arrogance of the poem's speaker establishes the rules of defining systems which, like Carroll's, are arbitrary and idiosyncratic. In this poem, she assigns new meaning to the proper name "Tsipora" - a common Hebrew first name, similar in meaning to the poet's first name ("Tsipora" means bird, "Yona" means "dove") - that instead now stipulates, arbitrarily, her unwanted feeling.

The speaker is infallible because the "right" mode of operation is "anyway I wish", independent of external rules aside from the speaker's inner sensations. Consequently, Wallach shares Humpty Dumpty's precarious position. On the one hand, the rules of her poems appear as arrogant and egocentric private speech, in which the sui generis (one-of-akind) speaker - much like Adam, the First Person - calls things by their "right name" within a hermetically sealed space. ${ }^{18}$ On the other hand, the confession posits Wallach not as a speaker unwilling to share her secrets with others, but (like Carroll) as one rather keen on communicative speech, sharing with others the "work's secrets" and enabling them to assign meaning by following the new playful "rules" she creates in poetry.

Lidovsky-Cohen's reading depicts the poem's naming mechanisms as a fully confident and somewhat "Romantic claim" that a name is expressive of the inner essence of the speaker's feeling. This reading, however, overlooks the playful tone of the poem's speaker. As, in another verse of the poem, the speaker is, herself, surprised that calling a sensation by a name comes "anew" each time (see endnote 16). This serves to challenge Lidovsky's claim of confidence and instead depicts a whimsical and somewhat sceptical narrative voice (Lidovsky-Cohen 2003).

By applying the clear logic of nonsense, the problem I had previously presented in "Sebastian" is resolved. We see how the speaker defines Sebastian: "Sebastian is/ a malady tender in warmth/ and compassion". It is a stipulative definition (though hazy, and indicative of the difference between Carroll's mathematical accuracy and Wallach's lyrical poetics). The definition replaces the meaning of Sebastian (a proper name of a person, with foreign connotations) with an "emotional state", and allows the speaker to spell out the essential components of Sebastian's new meaning. ${ }^{19}$ The poem - or symptoms of the "malady" at its 
centre - is about a "malady tender in warmth and compassion", a sexual and acute romantic malady, a sensation of pleasurable and merciful warmth.

This definition resolves the ontological problem of Sebastian's simultaneous existence and non-existence. ${ }^{20}$ Throughout the poem, the speaker describes a single failure to contract "Sebastian", namely to feel the tender warmth ("of Sebastian/ who never was"). That is to say, instead of being regarded as a proper name that denotes a specific person (which will indeed cause the ontological problem), "Sebastian" has changed its grammatical rule and is now "a sebastian", a common noun used to identify a general ailment contracted by the speaker several times. Being a common noun, "Sebastian" should be uncapitalized in the translation, written as "Sebastian" and "a Sebastian"; I chose to have it capitalized in the translation to emphasize the semantic confusion caused by the wordplay. The speaker had contracted this malady in the past ("in which Sebastian would always happen to me"), however not today ("today I came back from another town [...] and [Sebastian] didn't happen to me"). Thus, at the end of the poem, the speaker is left fantasizing about the "leader of the mustangs" within nature, in whose proximity she managed to once more feel the tender warmth which eluded her in the city on that particular day.

The poem's remaining descriptions are merely parallels honing the most elementary traits of the tenderly warm and merciful malady, as presented within the introductory definition. The double fantasy described at the poem's end is a "romantic" malady, a woman's fairly stereotypical fantasy of a rare encounter with a stereotypically virile male, "leader of the mustangs", who will allow her to re-experience the fragile and "tender warmth" she so desires. Namely, the romantic-sexual warmth, whose attempted realization is similar to erecting a phallic tower, as the poet wanted "to raise to his name [...] something like a house for archers". Visible from the house is the color pink, stereotypical of warm, fragile, and tender femininity ("slits through which one sees a pink city" [the emphasis is mine]). The realization attempt is abandoned by the speaker before consummation, as, right from the start, she shudders at the thought of conventional courtship in the city (the speaker "came back from another city", where "everything is painted and licked") - in stark contrast to the consummation stripped of slick mannerisms which is attainable only with the "leader of the mustangs" within nature.

Thus, Wallach's stipulative proper names create, as presented, a unique lingual system of their own: most are exotic, enigmatic, and intriguing names as are those of the odd creatures Carroll devised in poems such as "Jabberwocky". Most of the names Wallach interweaves into her poetry exist in previous linguistic systems (unlike the mostly invented words of "Jabberwocky"), primarily in the first name system of Christian saints. However, their "Christianity" turns out to be no more than a playful, humourous, and arbitrary hoax, reminiscent of Carroll's Humpty Dumpty.

\section{Off with his head!}

Additional use of the non-referential nonsense mechanism comes to prominence in the poem "Yonatan":

I'm running on the bridge

And the kids are after me

Yonatan

Yonatan they call out

A little blood

Just a little blood to wash down the honey

I agree to the pierce of a tack 


\author{
But the kids want \\ And they are kids \\ And I'm Yonatan \\ They cut off my head with a branch of \\ Gladiola and gather my head \\ With two branches of gladiola and wrap \\ My head with rustling paper \\ Yonatan \\ Yonatan they say \\ Really forgive us \\ We didn't imagine you were like that
}

(Lidovski-Cohen 2003: 50-51)

Yonatan, a child-cum-adult, is pursued by children who holler for "a little blood to wash down the honey" and behead him with a branch of gladiola - which the Hebrew word for is סיפ, literally meaning "sword". ${ }^{21}$ It is a materially impossible situation, identical to that embodied in the Queen of Hearts, among the most renowned characters Carroll wove into Alice's dream. On innumerable occasions throughout the story, the cruel card-queen seeks to kill off all the characters she dislikes, to Alice's great astonishment.

In his article "Horror and humor" (1999), Noel Carroll demonstrates how both horror and humour derive from mechanisms of incongruity between the spectator and the textdepicted world, through breaking the reader's horizon of expectations, and the categories of classification and signification. Therefore, the same type of incongruity can lead to either laughter or horror. What differentiates between them is that the comic text attempts to alienate us emotionally from the situation, so that we sense the violence as "unreal" (Carroll 1999). By doing so, we are able to cope with the dark source material, made light and comedic. As shown in regard to black humour, the comedic elements function in an almost satirical way, pointing to the absurdity of the world, by tackling subjects often considered serious and taboo, such as dying (c.f., e.g. Bloom and Hobby 2010). The comedic element thus has a psychological effect that helps us overcome anxiety (c.f. Safer 2010; Reich 1949).

Lewis Carroll does this:

'Hold your tongue!' said the Queen, turning purple.

'I won't!' said Alice.

'Off with her head!' the Queen shouted at the top of her voice. Nobody moved.

'Who cares for you?' said Alice, (she had grown to her full size by this time.) 'You're nothing but a pack of cards!'

(Carroll 1962 [1865]: 157)

Alice exposes the linguistic ploy which also underpins "Yonatan". That is, the actualization of metaphor: A pretence which exploits a logical lacuna within the definition applied to a particular term. In describing the operation of nonsense mechanisms, Yigal Schwartz writes: "nonsense [...] is the product of collision between commonsense, which is also common knowledge, and nonsense, in the service of a subversive practice. It is a practice exploiting a crack in the logical closure of some defined phenomenon" (Schwartz 2015: 752). ${ }^{22}$ In the case at hand, nonsense is created via confusion between the metaphorical and the literal straightforward use of a word. The word "queen" serves to signify two terms: it signifies a real, concrete, human flesh-and-blood queen, as well as a metaphorical card-queen, the Queen of Hearts. Lewis Carrol actualizes the metaphorical. He pretends the context in which the word "queen" is used metaphorically (as a card) is the context in which the word "queen" is used literally (as a flesh-and-blood queen), subverts mimetic common sense, and 
in its place posits another consistent system of order and rules: the card game around which the narrative of Alice in Wonderland is structured.

The beheading in Wallach's poem operates similarly, but leads to the opposite result. Wallach also pretends, subverts common sense, actualizes the metaphor and plays upon the tension between the use of the word "sword" in its real literal context, as an actual sword capable of chopping off heads, and its metaphorical use - the gladiola - which indeed resembles a sword, but is incapable of decapitation. It is "a flicker" of pretence that establishes a nonsensical space incongruent with our commonsense view of the world; a space in which the card-queen becomes a human queen without ceasing to be a card, and in the course of which the gladiola branch becomes a real sword without ceasing to be a branch. As long as Alice accepts this flickering, threatening, and nonsensical space, as well as the possibility that this card-queen can act as a flesh-and-blood queen, she can remain in Wonderland. Once she declines to accept, rebels and appeals to her commonsensical insight which rescues her from the horror of the unfamiliar violent reality - she wakes up, returns to the secure reality she had always known, and ends the horror. By contrast, Wallach leaves us inside the unreal flickering space, with her pretence in which the metaphor's actualization is unexplained and common sense comes not to our aid - the result is tragic and painful. The threats of execution were carried out, and Yonatan's head was indeed chopped off. As such, we remain within the threatening reality.

Sewell explains that in rejecting referentiality, nonsense compels a focus on words themselves, rather than on human elements, feelings, relationships - all the "real" matters that might cause the reader to emotionally identify with the situation (Sewell 1952).

This sense of alienation is what enables laughter, which replaces the alarming feeling likely to arise given the threatening character of the Queen. ${ }^{23}$ This allows us to cope with and make fun of our fears, turning the dark source material lighter.

Such emotional alienation is particularly essential in a text intended for children, who need reassurance that "everything is alright" and, as a target audience, must be taken into consideration; as the King of Hearts tells the Queen when she threatens to cut off Alice's head on a previous occasion ("consider, my dear: she is only a child", Carroll 1962 [1865]: 107). The text prevents identification by choosing words stripped of emotional or aesthetic associations, and by maintaining constant awareness of the work's fictionality; the situations described are far removed from what is familiar to us and therefore provoke no identification, and are, as Ruth Riess explains, experienced like reading or watching cartoons. ${ }^{24}$ The cardqueen is (literally and figuratively) a flat character, as are the other characters. And throughout the story, Alice knows there is no point in getting excited or alarmed over the queen, as she is only a playing card. Thus, our awareness is sustained that what is at stake is merely an illusory game pretending to be real; this is the premise of differentiation between the "actual" and "dream" world, between common sense and nonsense, as has been suggested by Schwartz. ${ }^{25}$

Wallach approaches the text from the opposite point of departure, and produces a sense of atrocity via our identification with the text. The text's classifying system is largely mimetic and fundamentally very human: it is children who pursue Yonatan. Unlike Carroll's alienated and differentiated card game, it is a familiar true-to-life system that goes wrong. On account of the relative mimetics, the system Wallach creates evokes our emotional identification, because the text deals with what Carroll attempts to evade at all costs - "real" emotional relations between human beings (for example, had the text been written "I'm running on the bridge and the gladiola branches are after me", the result would be more consistent with Wonderland). In terms of human relationships, Yonatan, in contrast to the rebellious, argumentative, and commonsensical Alice, consents to be a victim: he cedes to illogical, gruesome, and ironic violence. Thus, the text evokes emotions absent from Carroll's 
text: a sense of identification with and empathy for the victim, of pity, of shock, of ghastly dismay. These are intensified given the fact that the poem's childish element is not intended to moderate, amuse, or eliminate the sense of terror at the violence, on the grounds that these are "only kids", but rather, ironically, to reinforce and intensify these sensations. As Lidovsky-Cohen argues,

A sense of deep-rooted irony arises also from the portrayal of children as mean-spirited, bloodthirsty creatures. On every tradition a child seems to stand for unadulterated purity, freshness, simplicity and naturalness. In fact, one gets a sense of puerile innocence even in this poem when Yonatan refers to them as "[just] kids" and agrees to their bloody games.

(Lidovsky-Cohen 2003: 55)

Ultimately, the mimetic realness finds expression in how the children respond to Yonatan's fate at the end of the poem: "we didn't imagine you were like that", and the wrapping of his inanimate head in rustling paper. Such a response presumes, commonsensically, that Yonatan remained alive and his ability to overcome death is an exceptional, unique, and extraordinary event in the world described by the text - just as it would be in real life. Yonatan is thus portrayed as a martyr, a Jesus-like figure. He is both persecuted and worshiped by the children who are after his blood, dies and is resurrected at the end of the poem. Furthermore, the "pierce of a tack" that he agrees to is a childish reference to the stigmata, according to Tsamir (2006); and his name - "Yonatan" - the Hebrew pronunciation of "Jonathan", is a reference both to John the Baptist and to Yonatan, son of king Saul, who was beheaded (c.f., e.g. Tsamir 2006; Lachman 1994; Rattok 1997). Consequently, Yonatan himself comes through as a unique, one-of-a-kind character. The name "Yonatan" can be read as the masculine form of the poet's first name - "Yona", and thus may be regarded as her male or androgynous personification. As such, Wallach, too, is greatly manifested as a mythical, one-of-a kind figure. ${ }^{26}$

Yonatan's surprising resilience to violence is unlike Carroll's nonsensical world. There, as I have shown, it is only a recurrent routine, occurring in some differentiated Wonderland, a "nothing-to-get-alarmed-about" violent threat, with the rules and logical form of cartoons.

\section{Notes}

${ }^{1}$ Certain claims I make in this article have been previously presented in my soon to be published article in the Israeli Journal of Humour Studies. The article is based on my thesis, which was written under the supervision of Dr. Anat Weisman at Ben Gurion University of the Negev. I am truly thankful for Dr. Weisman's valuable guidance.

2 See e.g. Renan (1976: 46-54); Moked (1976: 27-28); Calderon (2009); Zilberman (1993); Lachman (1994: 142-154).

${ }^{3}$ In this article I am referring to the novels: L. Carroll (1962 [1865 \& 1871]), Alice's Adventures in Wonderland and Through the Looking Glass, Harmondsworth, Penguin Books.

${ }^{4}$ In 1967, a year before Yona Wallach published her first book, Jefferson Airplane's Rock classic "White Rabbit", describing an LSD trip entirely based on the Alice books imagery, became one of the identity markers of the Flower-Children generation. As Salina Mashiach explains, the song allied the "surreal", doubtful and rebellious atmosphere of the books with the reality as experienced by the flower-children (1995: 44-48).

${ }^{5}$ Schwartz (2015) called the meaning behind nonsense "consense".

${ }^{6}$ Moreover, Susan Stewart argues that nonsense and common sense are interdependent. Common sense in the hierarchy of social discourse is perceived as "real" and "important". Nonsense is an impediment to the categories of social signification. It threatens to deconstruct 
common sense. Hence, we classify nonsense as being "unreal" and "unimportant", capable of occurring only in Never-Never-Land, at the peripheries of society's everyday life (Stewart 1979).

${ }^{7}$ Humour derives from mechanisms of incongruity between the observer and the textual world, from breaking the reader's horizon of expectations and the categories of classification and signification - these being the mechanisms of nonsense. See, for example, Stewart 1979.

${ }^{8}$ For similar descriptions of Wallach's language, see Zilberman (1993); Raz Brakin (2010); Lidovsky-Cohen (2003); Moked (2011 [1976]).

${ }^{9}$ See e.g. Stav (2014); Yeshurun (1984: 105-117); Shabtai (1985/6: 15-22); Moked (2011 [1976]: 168-174); Zuckerman (1988 [Kol Israel 1986]: 28-34).

${ }^{10}$ The poem was translated by Esti Pritzker, especially for this article.

${ }^{11}$ On this matter, see Lecercle 1985; Lecercle 1994; Unger 2005.

${ }^{12}$ This meaning is called "stipulative meaning" or "stipulative definition". Stipulative definitions determine meaning for a new term and detail its properties, while entirely dependent on the speaker defining them. See Robinson 1950.

${ }^{13}$ See also Lecercle (1994).

14 In his Philosophical Investigations, Wittgenstein substantiated the idea that language is essentially a social phenomenon. In the framework of this conception, he protested against the notion of the speaker of a language as First Man, a notion by which the "inner intentionality" of the speaking subject determined the meaning of words, which Wittgenstein called "private language". For him it was impossible, as impossible as the right hand giving money to the left hand. Wittgenstein perceives language as a social function. He referred to it as a "language-game" where speakers learn to speak by following the linguistic rules. Thus, he claimed it is not possible to have "private language", because it is impossible know whether the speaker "really" followed the rules of the game properly, or merely thinks he has done so (Wittgenstein 1953).

15 The poem's first stanza: "Twas brillig, and the slithy toves/ Did gyre and gimble in the wabe; /All mimsy were the borogoves,/And the mome raths outgrabe" (Carroll 1962 [1871]: 276). The word "brillig" Humpty renders arbitrarily as meaning "four o'clock in the afternoon - the time when you begin broiling things for dinner" (Carroll 1962 [1871]: 276). It is worthwhile viewing the poem as an example of the play between form and content - the fact that its sentence structures are syntactically correct enables its understanding despite the absence of reference for the clear meaning of the words.

${ }^{16}$ This poem was also translated by Lidovsky-Cohen. However, I chose to use a translation by Esti Pritsker, who translated it especially for this article, as I thought it to be more accurate.

${ }^{17}$ I here produce the other parts of the poem - A: "Hello, you seem very familiar to me,/ I lived with you about two years ago/I saw you almost every day/ until your visage was almost erased,/ when people live together very often/visage is destroyed, except when/ a face is particularly festive/and you do not have a face like that./You have not changed. Not even the smell./ And we met in the same usual place./At first I did not notice that it was you,/ I mean I did not notice that/ something has really changed, in other words/ as if since then until now we have/ always been together, until something/ made me realize my mistake,/ maybe it is that I called you by your name and it came/ to me like new, by itself./ Like that (particular) self precisely" (Lidovsky-Cohen 2003: 27-28); B: "You were always in me/ sometimes without sometimes within/ suddenly you dashed out of me/ but, you are not startling./ You are so familiar/ that it takes time to see" (Lidovsky-Cohen 2003: 30). And part D: "It is impossible to end like this./ It is very distressing. There are words/ that are hard to say. There is a need/ to openly investigate the system./ The word loneliness in hard to say./ When desire 
is satisfied it is dismissed./ Unless the magnitude of its claim/ is ingenious./ The feeling contains its destruction./ As opposed to the verb, the adjective/ is the stability of the feeling./ Suddenly it can go on./ Therefore it is better to use the verb/ to mark the feeling/ and that's what was hard for me" (Lidovsky-Cohen 2003: 33).

${ }^{18}$ Wallach's poetic cycle models the speaker as a one-time character in categorical terms, as belonging to no category but its own. It does so by contrasting the obliterated ordinary "face" of the "addressee", unnoticed by the poem's speaker because "[she] has no singular face" and is "not stunning [...] so familiar/ that it takes time to see", with the singular unforgettable face of the speaker. And as such, it evokes the one-time figure of Humpty, the omnipotent speaker with the distinct and exceptional face, against Alice, who symbolizes the conventional and referential logic of "all the other people" and has an "ordinary" and easily forgettable face.

${ }^{19}$ To understand that it is a defining sentence we should examine its formalism, as suggested by Sewell's logical approach to nonsense. The sentence looks like the lexical and perfectly intelligible definition - "a cold is an illness with a fever and runny nose". Formally, the sentence has on the one hand the word being defined (the definiendum), namely Sebastian or "a cold"; and on the other, the properties applying to the defined term, which explain its meaning and are contained in its very definition (the definiens), in the case at hand, "a malady tender in warmth" or "a cold with a fever and a runny nose". I used the terms suggested by Robinson (1950).

${ }^{20}$ In her Lacanian reading, Inbal Raz-Brakin suggests that Sebastian is a name that rejects the immortalization attempt of language, a name that resists distinct boundaries and cancels its meaning in the line "never was". Hence, we have no choice but to enjoy its lack of meaning (Raz Brakin 2010). My reading shows the diametrical opposite: Sebastian is immortalized in language and the enjoyable "resistance" in his non-realization is no more than the non-realization of one of the times when the speaker did not contract the Sebastian malady.

${ }^{21}$ Under the present framework, I shall not go into a full analysis of this much analyzed poem. Wallach research perceives Yonatan - the Hebrew pronunciation of "Jonathan" - as a composite of Yonatan, son of King Saul, "Little Yonatan" - an Israeli nursery rhyme about a naughty boy who is being punished - and the poet's name in the masculine form, as her male or androgynous version. The accepted hermeneutic suggests that the deictic open ending, which enables multiple readings, conceals from us the fact that Yonatan is a Jesus-like figure, persecuted-revered by the children, who dies and "rises" at the end of the text, as he is wrapped in rustling paper and transformed into an aesthetic and cultic object. The children, who did not imagine he was "like that", namely transcendent and capable of overcoming death, ask his forgiveness and perhaps even regret their deeds (e.g. Tsamir 2006; Lachman 1994; Rattok 1997).

${ }^{22}$ Rachel Albeck-Gidron similarly phrases the humour of nonsense as humour that momentarily bungles our map of orientation, and is based on insane etymology, e.g. use of several possible meanings for the same word (Albeck-Gidron 2016).

${ }^{23}$ As Henri Bergson explains in his Laughter, feelings of identification are laughter's great enemies, because if we identify with the source of mockery, it is reasonable we would not laugh but rather pity him (Bergson 1921 [1911]).

${ }^{24}$ Ruth Riess distinguishes between the comical and silly aspect of nonsense and the "serious" aspect of sinister and violent situations as the deep structure of nonsense based on a violent, judgmental, and cruel world (Riess 1995).

${ }^{25}$ Schwartz analyzes the opening paragraph of The Little Prince and argues that the text retains the premise of differentiation between nonsense and common sense, and between the 
world of children and adults, which is momentarily undermined but is ultimately re-endorsed and reaffirmed more forcefully; aiming to calm us and signal that "everything is under control" and that we did not really adopt an illogical and subversive stance (Schwartz 2015). The approach taken by Carroll in Wonderland, through Alice's conscious and dismissive attitude towards the Queen, coheres with Schwartz' insight.

${ }^{26}$ As, for example, Ariel Hirschfeld's description of Yonatan as a one-of-a-kind Godgiven who resists categorization and his story nourishes Wallach's own figure (Hirschfeld 25/9/1992).

\section{References}

Albeck-Gidron, R. (2016). On Title Page Verso: Exploring the Third Option: A Critical Study of Yoel Hoffmann's Works [Hebrew]. Or Yehudah: Dvir.

Bergson, H. (1921 [1911]). Laughter: An Essay on the Meaning of the Comic, transl. C. Brereton \& F. Rothwell. London: Macmillan.

Bloom, H. \& Hobby B. (eds.). (2010). Dark Humor. New York: Bloom's Literary Criticism.

Calderon, N. (2009). The Second Day - On Poetry and Rock in Israel after Yona Wallach [Hebrew]. Or Yehudah: Dvir.

Carroll, L. (1962 [1865 and 1871]). Alice's Adventures in Wonderland and Through the Looking Glass. Harmondsworth: Penguin Books.

Carroll, L. (1977 [1896]). Lewis Carroll's Symbolic Logic, Part I, Elementary, 1896, Fifth Edition, Part II, Advanced, Never Previously Published: Together with Letters from Lewis Carroll to Eminent Nineteenth-century Logicians and to His "Logical Sister," and Eight Versions of the Barber-shop Paradox. Bertley III, W. W. (ed.). New York: C.N. Potter.

Carroll, N. (1999). 'Horror and humor'. The Journal of Aesthetics and Art Criticism 57 (2/4). Aesthetics and Popular Culture, pp. 145-160.

Hancher, M. (1981). 'Humpty Dumpty and verbal meaning'. The Journal of Aesthetics and Art Criticism 40 (1/2), pp. 49-58.

Hirschfeld, A. (25/9/1992). 'Le'olam sh-lo'esh'ma et kolo ha'matok shel ha'elohim' ("I will no longer hear the sweet voice of God") [Hebrew]. Ha'aretz, p B8.

Holquist, M. (1999 [1969]). “What is a Boojum?" Nonsense and Modernism'. Yale French Studies 96, pp. 100-117.

Lachman, L. (1994). 'Al ha'ani be'shirat Yona Wallach' (“On the 'Self' in Yona Wallach's Poetry”) [Hebrew]. Hadarim 11, pp.142-154.

Lecercle, J.-J. (1985). Philosophy Through the Looking Glass: Language, Nonsense, Desire. London: Hutchinson.

Lecercle, J.-J. (1994) Philosophy of Nonsense: The Intuitions of Victorian Nonsense Literature. London: Routledge.

Lidovsky-Cohen, Z. (2003). Loosen the Fetters of Thy Tongue Woman: The Poetry and Poetics of Yona Wallach. Ohio: Hebrew Union College Press.

Mashiach, S. (1995). 'Klasika le'yeladim: Peter Pan, Michael Jackson u'she'elat ma'amada shel ha'sifrut la'yeladim' ("Children's classics: Peter Pan, Michael Jackson and the status of children's literature”) [Hebrew]. Moznaim 4, pp. 44-48.

Moked, G. (2011 [1976]). 'Shira ke'chidush shel mashma'ut' ("Poetry as renewal of meaning") [Hebrew], in In Real Time (96 Essays, Articles, Reviews and Notes on Hebrew Literature of the State Generation), Tel Aviv: Achshav, pp.168-174.

Moked, G. (1976). 'Gufey "Dvarim" - chalufa le'metaphorot?' ("Bodies of Things - an alternative to metaphors?") [Hebrew]. Moznaim 2, pp. 27-28. 
Rattok, L. (1997). Angel of Fire: The Poetry of Yona Wallach [Hebrew]. Tel Aviv: Hakibbutz Hameuchad.

Raz Brakin, I. (2010). Signs of Enjoyment: A Lacanian Reading in the Poetry of Yona Wallach and David Avidan [Hebrew]. Ramat Gan: Bar Ilan University.

Riess, R. (1995). Poetical Aspects of Nonsense Poetry in Hebrew. Ranat Gan: Bar Ilan University MA thesis.

Reich, A. (1949). 'The structure of the Grotesque-Comic Sublimation'. Bulletin of the Menninger Clinic 13 (5), pp. 160-171.

Renan, Y. (1976). 'Bniyatan shel afsharuyot hargasha: aspectim be'shireya harishunim shel Yona Wallach' ("The construction of possibilities of feeling: Aspects in Yona Wallach's early poems") [Hebrew]. Hasifrut 22, pp.46-54.

Robinson, R. (1950). Definition. Oxford: Oxford University Press.

Safer, B. E. (2010). 'Alienation and black humor in Philip Roth's "Exit Ghost". Studies in American Jewish Literature 29. A Special Issue in Honor of Sarah Blacher Cohen, pp. 139-147.

Sewell, E. (1952). The Field of Nonsense. London: Chatto and Windus.

Shavit, Z. \& Even-Zohar B., (1996). Just Childhood: Introduction to Poetics of Children's Literature [Hebrew]. Tel Aviv: Open University.

Shabtai, A. (1985/6). 'Al Yona Wallach' (“About Yona Wallach”) [Hebrew]. Hadarim 5, pp.15-22.

Schwartz, Y. (2015). 'Common-sense, nonsense ve'trauma be'yetsirato shel Yoel Hoffman' ("Common-sense, nonsense and trauma in the works of Yoel Hoffman") [Hebrew]. El Prezenta 8 (2/3). Dameta LeTamar: Studies in Honor of Tamar Alexander. Beer Sheva: Ben Gurion University of the Negev, pp. 745-774.

Stav, S. (2014). Reconstructing Daddy: Fathers and Daughters in Modern Hebrew Poetry [Hebrew]. Tel Aviv: Dvir.

Stewart, S. (1979). Nonsense: Aspects of Intertextuality in Folklore and Literature. Baltimore: Johns Hopkins University Press.

Tsamir, H. (2006). In the Name of the Land: Nationalism, Subjectivity and Gender in the Israeli Poetry of the Statehood Generation [Hebrew]. Jerusalem: Keter.

Unger, H. (2005). 'Sense ve-nonsense ba-omanuyot' ("Sense and Nonsense in the Arts") [Hebrew]. Tel Aviv: Tel Aviv University, Faculty of Arts, Rector's Series lecture.

Weisman, A. (2014). 'Wallach, Yona' [Hebrew], in Stavi, Z. \& Schwartz, Y. (eds.), The Heksherim Lexicon of Israeli Authors, Or Yehuda \& Beer Shevah: Dvir \& Ben Gurion University, pp.377-380.

Wittgenstein, L. (1953 [1953]). Philosophical Investigations, transl. G.E.M. Anscombe, Oxford: B. Blackwell.

Yeshurun, H. (1984). 'Yona Wallach, April 1984: re-ayon' ("Yona Wallach, April 1984: Interview") [Hebrew]. Hadarim 4, pp.105-117.

Zilberman, D. (1993). Hebrew is a Language Bathing: 6 Chapters on Yona Wallach's Poetry [Hebrew]. Tel Aviv: Yaron Golan.

Zuckerman, I., 1988 [Kol Israel 1986]. 'Kolo ha-matok shel Elohim: tochnit radio al shirata u dmuta shel Yona Wallach' ("The sweet voice of God: a radio program on the poetry and figure of Yona Wallach") [Hebrew], Prosa 100, pp.28-34. 